\title{
PRÁTICAS DE EDUCAÇÃO AMBIENTAL: ESTUDANTES CIENTISTAS
}

Isabel Cristina Bohn Vieira ${ }^{1}$

Carla Silvanira Bohn²

Eduardo Augusto Werneck Ribeiro ${ }^{3}$

Resumo: Este artigo apresenta uma proposta de aplicação teórico-prática, com especial atenção aos recursos hídricos, exercitando a aplicação do método científico na educação. A proposta descreve um modelo de roteiro de Estudante Cientista, configurando um arcabouço atrativo e didático para o desenvolvimento de projetos de ensino, sob a perspectiva colaborativa, participativa. Essa aplicação objetiva que acadêmicos e profissionais da educação fundamentem a cientificação de conceitos através de atividades didáticas práticas na Área de Ciências da Natureza, além de envolver e encorajar os estudantes às experiências investigativas na busca por soluções de problemas ambientais e sociais vigentes, em pleno exercício da cidadania.

Palavras-chave: Roteiro Teórico-prático; Método Científico; Estudante Cientista; Ciências da natureza.

Abstract: This article presents a proposal for a theoretical-practical application, with special attention to water resources, exercising the application of the scientific method in education. The proposal describes a Student Scientist script model, setting up an attractive and didactic framework for the development of teaching projects, from a collaborative, participatory perspective. This application aims that academics and education professionals base the scientification of concepts through practical didactic activities in the Area of Natural Sciences, in addition to involving and encouraging students to investigative experiences in search of solutions to current environmental and social problems, in full exercise of citizenship.

Keywords: Theoretical-practical script; Scientific Method; Student Scientist; Natural Sciences.

${ }^{1}$ Instituto Federal Catarinense. E-mail: isabelbohnvieira@gmail.com.

Link para o Lattes: http://lattes.cnpq.br/1826501477144572

2Universidade Federal de Santa Catarina. E-mail: carlabws@gmail.com.

Link para o Lattes: http://lattes.cnpq.br/5943938234226549

${ }^{3}$ Instituto Federal Catarinense. E-mail: eduardo.ribeiro@ifc.edu.br.

Link para o Lattes: http://lattes.cnpq.br/0958574773546143

Revbea, São Paulo, V. 16, № 3: 18-37, 2021. 


\section{Introdução}

$\mathrm{Na}$ contemporaneidade, as evidências que a sociedade vivencia uma crise ambiental são cada vez mais contundentes. Na condição de sujeitos, sofremos o impacto desses problemas ambientais que comprometem a qualidade de vida e a saúde de toda a população (PICCOLI et al., 2016). Para minimizar essa crise ambiental não bastam apenas iniciativas empresariais ou governamentais, é necessária a participação de todos os cidadãos, munidos de informações cientificas acerca das consequências que a degradação do ambiente pode acarretar sobre sua própria vida e na vida de seus familiares. A disseminação do conhecimento científico é a base para essa fundamentação e para reivindicações de soluções ecologicamente viáveis hoje e no futuro próximo. Assim, o objetivo desse artigo é contribuir para que acadêmicos e profissionais da educação possam fundamentar a cientificação de conceitos através de atividades didáticas práticas na Área de Ciências da Natureza, conforme a Base Nacional Comum Curricular, com foco no ensino Fundamental II, estabelecido pelo Ministério da Educação.

O presente material, apresentado em forma de roteiro, foi elaborado visando propor abordagens teórico-práticas, com especial atenção aos recursos hídricos, configurando um arcabouço atrativo e didático no que tange a possibilidade do desenvolvimento de projetos de ensino sob a perspectiva colaborativa e participativa entre educandos e educadores, estimulando assim, o exercício da cidadania em busca por soluções de problemas ambientais e sociais vigentes.

Descortina-se a seguir, a descrição da proposta deste artigo dividida em duas principais seções, o roteiro contextual do Estudante Cientista, contemplando os objetivos da aprendizagem, bem como a competência da Base Nacional Comum Curricular e seu respectivo contexto nos Temas Contemporâneos Transversais (TCTs), especificamente na macro área Meio Ambiente, abordando textos motivadores que contemplam os temas: o que é ciência, seu papel para o progresso da humanidade, um breve reconhecimento de território. Estes, fundado com a questão disparadora, que engatilhará 0 trabalho progressivo subsequente. $\mathrm{Na}$ segunda seção, ilustra-se o roteiro de trabalho, o passo a passo, desde o emprego do método científico, na forma de texto motivador, até a proposta de sistematização de análise dos resultados. Espera-se assim, contribuir com os incansáveis esforços dos profissionais do ensino que primam por atividades inovadoras e diversificadas possibilitando o exercício da cidadania em busca por soluções de problemas ambientais e sociais vigentes, assegurando o bem-estar de todos.

\section{Roteiro contextual do estudante cientista}

O governo federal brasileiro, visando estruturar e orientar o currículo na Educação Básica e, buscando o desenvolvimento na integralidade, biológico, 
psicológico e social do educando, deliberou alguns documentos norteadores do ensino ao longo de 24 anos de história e que se efetivam até o atual momento.

Cronologicamente, o artigo 26 da Lei $n^{\circ}$ 9.394, de 20 de dezembro 1996, Lei de Diretrizes e Bases da Educação Nacional (LDB), regulamentou uma base nacional comum para a educação básica e incluiu a Educação Ambiental como uma diretriz para o Ensino Fundamental (BRASIL, 1996). Em 1998, são alicerçados em dez volumes os Parâmetros Curriculares Nacionais (PCNs), para o Ensino Fundamental, $6^{\circ}$ ao $9^{\circ}$ ano com a intenção de ampliar e aprofundar o debate educacional que evolvesse escola, pais, governo e sociedade, incorporando a temática ambiental em todas das disciplinas (BRASIL, 1997). Em 13 de julho de 2010, a Resolução n4 define as Diretrizes Nacionais Gerais para a Educação Básica (DCNs) com o objetivo de orientar o planejamento curricular das escolas e dos sistemas de ensino (BRASIL, 2013). $\mathrm{O}$ artigo $1^{\circ}$ da Lei $\mathrm{n}^{\circ} 13.005$, de junho de 2014, regulamentou o Plano Nacional de Educação (PNE), estabelecendo 20 metas para a melhoria da qualidade da Educação Básica, sendo que quatro delas discorriam sobre a construção da Base Nacional Comum Curricular (BRASIL, 2014). Em 17 de junho 2015, pela portaria $n^{\circ} 592$ foi instituído uma comissão de especialistas para a elaboração da Proposta da Base Nacional Comum Curricular, mas somente em 14 de dezembro de 2018 o ministro da Educação Rossieli Soares homologou o documento Base Nacional Comum Curricular (BNCC) em todas as etapas de ensino.

A Base Nacional Comum Curricular (BNCC) é um documento de caráter normativo que define o conjunto orgânico e progressivo de aprendizagens essenciais que todos os alunos devem desenvolver ao longo das etapas e modalidades da Educação Básica. A Base estrutura os currículos dos sistemas e redes de ensino das Unidades Federativas, como também as propostas pedagógicas de todas as escolas públicas e privadas de Educação Infantil, Ensino Fundamental e Ensino Médio, em todo o Brasil (BRASIL, 2017). Esta se articula conforme os termos da LDB, das DCNs e do PNE, estabelecendo conhecimentos, competências e habilidades que, espera-se, sejam desenvolvidas em todos os estudantes ao longo da escolaridade básica, valorando os princípios éticos, políticos e estéticos somados aos propósitos que direcionam a educação brasileira para a formação humana integral e para a construção de uma sociedade justa, democrática e inclusiva.

Estruturada na BNCC, grande área de Ciências da Natureza é vislumbrada como um empreendimento humano de conhecimento científico como provisório, cultural e histórico, a fim de dominar processos, práticas e procedimentos da investigação científica, de modo a debater questões científicas, tecnológicas, socioambientais, colaborando para a construção de uma sociedade justa, democrática e inclusiva.

A Educação Ambiental emerge dessa construção histórica educacional, contemplada na área de Ciências da Natureza e nos Temas Contemporâneos Transversais especificamente na macroárea Meio Ambiente, outrora conhecido 
como PCNs, visando 0 aprofundamento intelectual de seus atores (MINISTÉRIO DA EDUCAÇÃO, 2019). A Educação Ambiental adentra na integração da complexidade biológica, psicológica, cultural e social, transformando vidas, transcendendo para além do contexto escolar, fundamenta-se no diálogo, na reflexão, nas experiências individuais e coletivas e na observação do meio que as cercam.

Segundo Carvalho (2004), é preciso superar a dicotomia entre natureza e sociedade para que haja relações de interação permanente entre a vida humana social e a vida biológica da natureza. Por suposto, a complexidade das diferentes concepções e práticas existentes, no que diz respeito à postura mais crítica em relação à temática ambiental, faz-se necessário uma gestão democrática do currículo pautado em documentos normativos (BNCC) para um contexto que abranja espaços físicos extramuros, com arcabouço teórico e prático fortalecendo o desenvolvimento da ciência e do método científico como educandos protagonistas, ou seja, como estudantes cientistas.

No âmbito educacional, para que essa dicotomia seja superada, planejar as ações pedagógicas é fundamental. O processo exige pensar na realidade que se deseja transformar, tendo em vista que, seus idealizadores precisam entender o "para quê" interferir e "o quê" se pretende repensar, para que haja mudanças no processo. Alcançar os objetivos de um planejamento depende do engajamento e parceria entre todos os evolvidos, ou seja, pais, alunos, professores, gestores, coordenadores e comunidade escolar, pois planejamento educacional não pode ser tratado como um processo isolado. Faz-se mister conhecer a realidade de inserção do contexto social dos envolvidos para construção de um currículo abrangendo as concepções filosóficas, psicológicas e pedagógicas do ensino (WOLLMANN; SOARES; ILHA, 2015).

Destarte, o planejamento educacional deve ser o instrumento norteador de toda essa construção e de formação, precisa ser contínuo, dinâmico flexível e inovador, sendo imprescindível estabelecer objetivos claros e exequíveis das ações escolares, para que outrora, passe a produzir conhecimentos que proporcionem a apreensão da realidade vivenciada, resgatando 0 comprometimento social e a incitação, por parte dos educandos, ao ato de aprender e atuar socialmente.

Logo, o que se pode inferir é que ações planejadas consubstanciam a educação e por consequência seus atores. Isso implica traçar objetivos de aprendizagem que conduzam a construção e a reconstrução dos saberes, que evidenciem suas finalidades, seus conteúdos e suas metodologias, partindo sempre do conhecimento sensível ou empírico para o conhecimento espiritual ou intelectual. Abordando essa concepção inovadora de ensino, sob a perspectiva colaborativa e participativa entre educandos e educadores assegurados pelo documento normativo BNCC e TCTs, descreve-se o roteiro subsequente. 
Tendo isto posto, vamos apresentar o roteiro. O roteiro é composto por quatro textos motivadores, uma seção que discute "O que é a ciência?", "O papel da ciência para a humanidade" e "Conhecendo nosso território" e a outra que apresentará o "Emprego do método científico" e a "Proposta de sistematização e avaliação dos resultados", sendo que partimos dos objetivos da aprendizagem e da competência da Base Nacional Comum Curricular.

\section{a) Objetivos da aprendizagem}

- Reconhecer o método científico como base para o desenvolvimento da ciência;

- aplicar o método científico mediante estudo de caso, incluindo a investigação, a reflexão e a análise crítica;

- desenvolver o conhecimento científico a partir do exercício intelectual, recorrendo a sensibilização da aprendizagem prática.

\section{b) Competência da Base Nacional Comum Curricular}

(2) Pensamento científico, crítico e criativo.

Exercitar a curiosidade intelectual e recorrer à abordagem própria das ciências, incluindo a investigação, a reflexão, a análise crítica, a imaginação e a criatividade, para investigar causas, elaborar e testar hipóteses, formular e resolver problemas e criar soluções (inclusive tecnológicas) com base nos conhecimentos das diferentes áreas (BRASIL, 2017).

Para implementar o roteiro, apresenta-se a sequência de textos motivadores que criarão o ambiente para o surgimento de questões com os alunos.

\section{Texto motivador 1: 0 que é ciência?}

A etimologia da palavra CIÊNCIA (do latim scientia = conhecimento), assim como do verbo scire $=$ saber, indica a origem mental do conhecimento, ou seja, a Ciência é uma atividade que se origina por meio de nossos pensamentos e concepções, sobre os fenômenos que observamos (CIÊNCIA, 2020). No Dicionário Michaelis, encontramos como: "reunião de saberes organizados, obtidos por observação, pesquisa ou pela demonstração de certos acontecimentos, fatos, fenômenos, sendo sistematizados por métodos ou de maneira racional: as normas da Ciência".

A Ciência é uma manifestação da cultura que visa o entendimento do mundo. A Filosofia pode ser considerada como a "base da Ciência", por ser mais antiga e por fornecer os princípios básicos do pensamento científico. A diferença é que, enquanto o filósofo procura entender o mundo através da 
observação, raciocínio e contemplação, o cientista procura entender o mundo por meio de observações e experiências sobre as causas dos fenômenos naturais (OMNĖS, 1996). Apesar de terem funções diferentes, elas, de alguma forma se complementam. Para compreendermos onde se iniciou a Ciência e por que ela está associada à Filosofia, podemos estudá-la em diferentes períodos históricos (Figura 1).

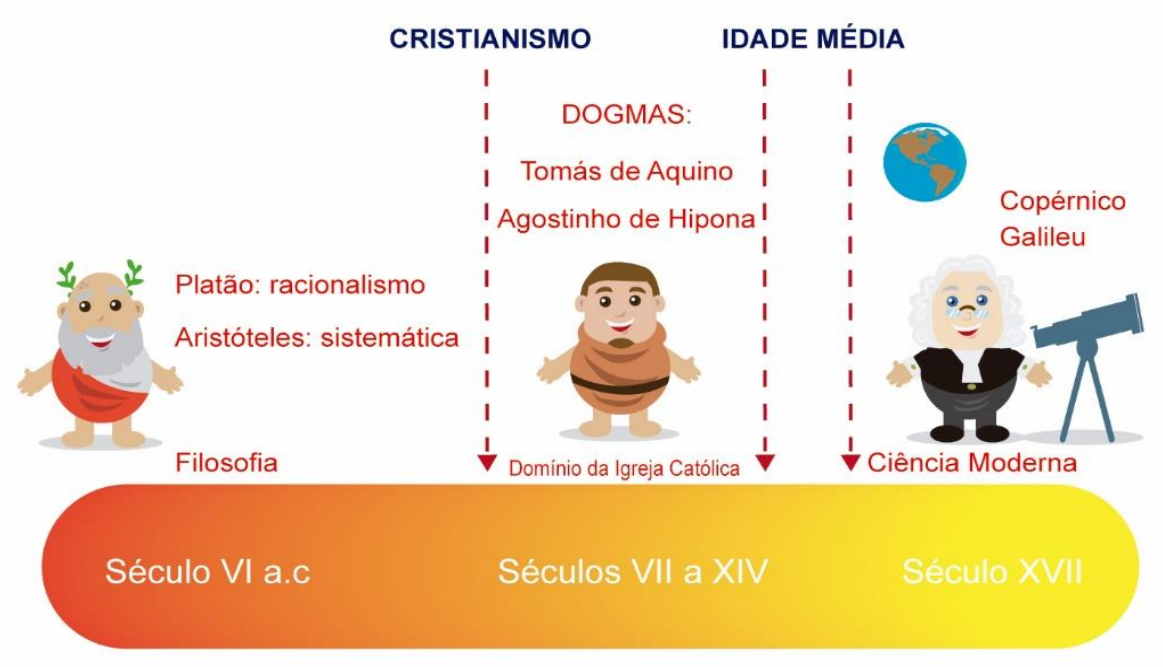

Figura 1: Linha do tempo do processo histórico da Filosofia à Ciência.

Fonte: Autores (2020).

A Ciência filosófica iniciou em tempos antigos (século VII a.C.), através de reflexões elaboradas por filósofos gregos como Platão (cerca de 428-327 a.C.), cuja filosofia enfatizava o conhecimento da essência das coisas e dos objetos (razão). No mesmo período, Aristóteles (384-322 a.C.), que começou sua carreira como um discípulo de Platão, criou sua própria linha de pensamentos e passou a dar maior importância ao conhecimento obtido a partir da observação e sistematização, sendo a essência (razão) menos importante. Com o fim do Império Romano, uma nova era filosófica liderada por Tomás de Aquino e Aurelius Agustinus (Agostinho de Hipona ou Santo Agostinho) fundiu as principais ideias filosóficas da época (principalmente as aristotélicas) com a Filosofia Cristã. Com o poder político crescente da Igreja Católica, estas filosofias cristãs passaram a ser consideradas verdades absolutas e inquestionáveis (dogmas). A imposição de dogmas pelo poder dominante da Igreja fez com que o mundo ocidental mergulhasse rapidamente no que se denominou de "Idade das Trevas" (Idade Média, entre os séculos V e XV). Neste período, a Igreja considerava indagações sobre fenômenos naturais, que não fossem explicadas pelos dogmas, como frutos de bruxarias e poderes ocultos, o que inibia as iniciativas de explicações científicas (VIDAL; FARIA FILHO, 2003). 
Passados alguns séculos, Nicolau Copérnico (1473-1543), com sua teoria do heliocentrismo, trouxe uma transição abrupta no conhecimento. Algumas décadas mais tarde, no começo do lluminismo ou do Renascimento (1571-1630), Johannes Kepler contribuiu para a fusão das ideias aristotélicas com as platônicas. Neste período, Galileu Galilei (1564- 1642), que foi um marco da revolução científica, saiu do desenvolvimento da Filosofia para a Ciência Moderna, rejeitando os dogmas impostos pela Igreja Católica e propondo o método de experimentação como "o desenvolvimento científico". O marco para o surgimento da Ciência Moderna é conhecido então, como Revolução Científica, ocorrida na Europa entre os séculos XVI e XVII com o desenvolvimento das etapas do método científico. Assim a Modernidade, ficou conhecida como Renascentismo, onde o conhecimento empírico passa a se associar ao conhecimento científico, fundamentando a superioridade explicativa fornecida pela Ciência, modificando-se radicalmente a compreensão e a concepção teórica de mundo, ciência, conhecimento e método (DA CIÊNCIA, et al., 2006)

No início do século XX as ideias de Albert Einstein (1879-1955) e Karl Popper (1902-1994) revolucionaram a concepção de ciência e método científico, propostos pela Modernidade (DA CIÊNCIA, et al., 2006). Os princípios tidos como incontestáveis no século passado foram cedendo seu lugar à atitude crítica, refutável ou falseável. A partir deles, desmistificou-se a concepção de que o método científico deveria ser regulado por normas rígidas, em que o investigador deve seguir para a produção do conhecimento científico. $\mathrm{Na}$ ciência contemporânea, a pesquisa é resultado decorrente da identificação de dúvidas e da necessidade de elaborar e construir novas respostas para esclarecê-las. A investigação científica desenvolve-se porque há necessidade de construir uma possível resposta ou solução para um problema, decorrente de algum fato ou conjunto de conhecimentos teóricos.

A concepção contemporânea da ciência está muito distante das visões aristotélicas e moderna. A contemporaneidade preconiza o saber-fazer, conhecimento para competência, a produção tecnológica com soluções rápidas para nossos entraves diários. Contamos com uma gama de informações em base de dados, equipamentos como: satélites, drones, microscópios ou computadores, todos à nossa disposição para repensar, recriar a ciência e melhorar o ambiente que deixaremos para as futuras gerações (RAMOS; ROSA, 2008). É a partir desta concepção atual que iremos contribuir na construção de agentes transformadores do pensar e do ambiente!

\section{Texto motivador 2: O papel da ciência para o progresso da humanidade}

O desenvolvimento da Ciência proporciona importantes descobertas sobre o mundo que vivemos. A ciência é indispensável para o progresso e a continuidade da humanidade e seria difícil imaginarmos o mundo atual sem as contribuições do conhecimento científico. 
O pesquisador ou cientista é aquele que usa a razão (raciocínio, aprendizado, compreensão, ponderação, julgamento) e a lógica (formulação de hipóteses que visam determinar o que é ou não verdadeiro) na pesquisa, aplicando assim, as diversas áreas do conhecimento: Ciências Biológicas; Ciências da Saúde; Ciências Agrárias; Ciências Exatas; Engenharias e Computação; Ciências Humanas; Ciências Sociais Aplicadas; Linguagens e Artes (CARVALHO, 2004).

O método científico é um conjunto de normas que serão empregadas para identificar os procedimentos que deverão ser utilizados para a realização de uma pesquisa científica. De modo geral, a proposta do método científico é ter um conjunto de regras básicas que serão utilizadas a fim de produzir novos conceitos, responder às nossas perguntas ou, talvez, corrigir ou ampliar conhecimentos já existentes (SHIGEYOSI, 2018).

O emprego do método científico se inicia com a observação atenta sobre algo que nos interessa conhecer (fenômenos físicos, químicos, biológicos, sociais, entre outros) e com a investigação das possíveis causas da manifestação do fenômeno que estamos interessados em conhecer. Afinal, a base do processo de construção da ciência ou do conhecimento é a dúvida e a curiosidade (Figura 2).

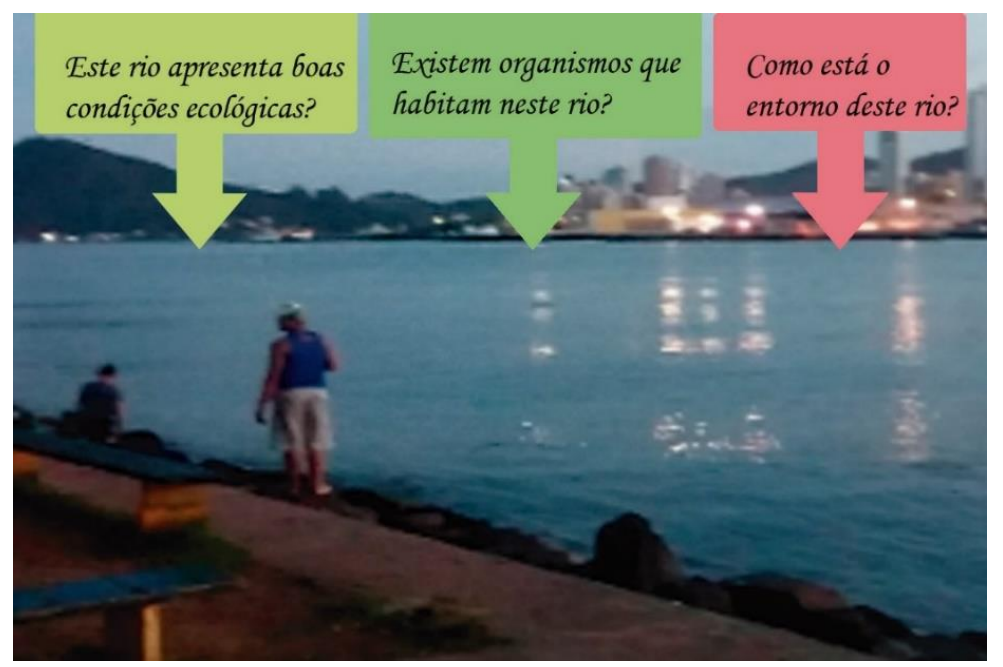

Figura 2: Indagaç̃ões que podem ser avaliadas para montagem de um projeto científico.

Foto: Rio Itajaí-Açu, SC, organizado pelos autores (2020).

A partir de questões é possível formular uma ou mais hipóteses com o objetivo de compreender um fenômeno. Essa hipótese deve estar embasada teoricamente (leitura) e, se a hipótese for comprovada, talvez possa até ser transformada em lei. Caso contrário, se ela não for comprovada, poderá ser revista ou até ser descartada para elaborar uma segunda hipótese, diferente daquela inicial.

Portanto, para criar um embasamento teórico, a fim de entender o seu problema, deve-se procurar textos que tratem sobre o tema de interesse, 
baseando-se em diferentes leituras e evidências. Esse é um passo muito importante de aplicação do método científico.

Uma forma sistemática para dar início à pesquisa científica é a aplicação de uma ferramenta chamada "mapa mental". O mapa mental é um diagrama que mostra a relação entre os elementos de seu projeto: observação de evidências, pergunta de trabalho, hipóteses (uma ou mais) e previsão (s) (FRANÇA, 2019). A utilização do mapa mental é muito importante na proposição de um projeto, pois este ajuda a organizar as ideias de forma ordenada.

A Figura 3 mostra um exemplo de sistematização de metodologia científica, na forma de mapa mental.

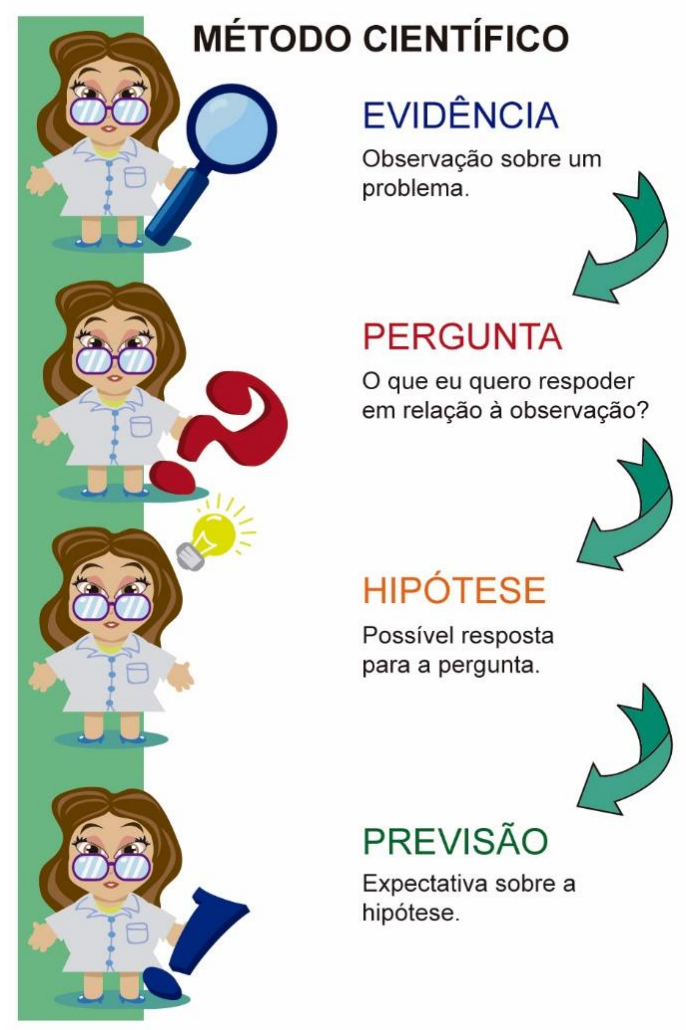

Figura 3: Exemplo de sistematização da pesquisa científica utilizando o mapa mental.

Fonte: Autores (2020).

De modo geral, é importante ter em mente que, na Ciência, nada é "para sempre", as causas dos fenômenos como hoje as conhecemos, com o desenvolvimento da pesquisa e das tecnologias de investigação, amanhã poderão ser outras. Afinal, o conhecimento é efêmero e somos dinâmicos, outro cientista poderá, no futuro, provar que sua teoria foi refutada. 


\section{Texto motivador 3: Conhecendo nosso território}

Conhecer o território em que vivemos é essencial para reconhecermos geograficamente onde estamos inseridos, bem como identificar e compreender a dinâmica social e as questões de saúde pública que nos cercam.

A ocupação territorial humana se deu, historicamente, em áreas próximas à água (especialmente rios e lagos) pela facilidade de sua captação e desenvolvimento das atividades humanas básicas (SILVA FERREIRA, 2014).

Os problemas hídricos começaram a partir do momento em que, além de sua proximidade facilitar a captação para o uso deste recurso, também facilita o aumento da degradação de suas condições ecológicas, como o lançamento de lixo bruto e o descarte de esgotos sem tratamento, ocasionados pelo crescimento em exponencial da população.

A importância do estudo da água atualmente, englobando seu destino e as condições para utilização humana, têm se tornado uma preocupação para o progresso da humanidade (VIEIRA, 2019). Então, tomando como base o método científico para reconhecermos melhor nosso território e desenvolvermos ciência, precisamos estudar alguns conceitos básicos, conforme propostos na Tabela 1.

Tabela 1: Conceitos-chave.

\begin{tabular}{|c|c|}
\hline \multicolumn{2}{|r|}{ CONCEITOS BÁSICOS } \\
\hline Território & $\begin{array}{l}\text { reúne noções de vida, de espaço social e de espaço vivido, podendo ainda ser interpretado como resultado } \\
\text { de uma apropriação político-econômica e/ou simbólico-cultural do espaço por grupos sociais que imprimem } \\
\text { uma representação particular a este espaço a partir de uma construção social e histórica. }\end{array}$ \\
\hline $\begin{array}{l}\text { Ecologia } \\
\text { Aquática }\end{array}$ & $\begin{array}{l}\text { estuda as interaç̃̃es dos organismos entre si e com as condições fisicas e químicas em um ecossistema } \\
\text { aquático. Essestipos de ecossistemas são caracterizados por teremágua em sua constituição como: mares, } \\
\text { oceanos, estuários, córregos, rios, lagos, pântanos, fontes naturais de água quente, geleiras, minas ou } \\
\text { afloramentos de água e todos os organismos que neles vivem }\end{array}$ \\
\hline $\begin{array}{l}\text { Bacia } \\
\text { hidrográfica }\end{array}$ & $\begin{array}{l}\text { corresponde a um espaço geográfico de área total de drenagem emumecossistema aquático principal, seus } \\
\text { afluentes e subafluentes. Uma bacia hidrográfica abriga um conjunto hierárquico de rios, ou seja, } \\
\text { naturalmente se inicia com rios de menor volume de águas (a partir das nascentes) que deságuam em rios } \\
\text { de maior volume sucessivamente, até atingirem o maior rio que se encontra encaixado no vale principal até } \\
\text { a região de foz (oceano). }\end{array}$ \\
\hline Hábitats & $\begin{array}{l}\text { são locais espećficos ou regiões onde se deservolvem ou vivem seres vivos de forma organizada. O habitat } \\
\text { oferece as condiç̃os climáticas, físicas e alimentares adequadas para o deservolvimento de uma } \\
\text { determinada espécie. }\end{array}$ \\
\hline Assoreamento & $\begin{array}{l}\text { é o acúmulo de sedimentos: areia, entulho e/ou lixo no leito dos lagos, rios e demais cursos d̛água. } \\
\text { Fenômeno este, provocado naturalmente ou por influência humana. }\end{array}$ \\
\hline $\begin{array}{c}\text { Eutrofizaçäo } \\
\text { artificial }\end{array}$ & $\begin{array}{l}\text { processo dinâmico que resulta em modificações qualitativas e quantitativas da entrada natural de nutrientes } \\
\text { (especialmente nitrogênio e fósforo) nos ecossistemas aquáticos continentais que ocasiona modificações na } \\
\text { diversidade aquática. Está diretamente relacionada ao aumento da população (esgoto) e da industrialização, } \\
\text { ao uso de fertilizantes na agricultura e de produtos de limpeza que contêm sabão em pó e detergentes. }\end{array}$ \\
\hline Mata Ciliar & $\begin{array}{l}\text { são florestas, ou outros tipos de cobertura vegetal nativa, que ficam às margens de rios, igarapés, lagos, } \\
\text { olhos d'água e represas. O nome "mata ciliar" vem do fato de serem tão importantes para a proteção de rios } \\
\text { e lagos como são os ćlios para nossos olhos. Ela é protegida pelalei } 4771 \text { de 15/09/1965, considerada pelo } \\
\text { Código Florestal "área de proteção pemanente". }\end{array}$ \\
\hline
\end{tabular}

Fonte: CABRAL, 2005; CCOPA, 2003; PORTO, 2008; VIEIRA, 2019. Organizado pelos autores (2020). 
As atividades antrópicas e aglomerações urbanas implicam na modificação de características naturais específicas do meio aquático. Localmente, obras como as de canalizações e de pavimentação e o desmatamento afetam diretamente à capacidade de infiltração da água no solo, a evaporação, o escoamento superficial e quebra da barreira dos poluentes lixiviados, causados pela falta da mata ciliar em torno do rio, afetando negativamente o funcionamento de bacias hidrográficas e por consequência a qualidade da água (VIEIRA 2019).

Neste contexto, identificar e reconhecer o território em que vivemos é primordial para garantir a preservação do meio. A partir dos conceitos que aprendemos, poderemos começar a gestão de recursos hídricos em formato de construção de planos de ação para controle e manejo de ecossistemas aquáticos, especialmente os continentais, aplicando o método científico.

Dessa forma, seremos uma sociedade mais ativa e participativa, pensando em território como espaço social, vivido e dinâmico! Diante do exposto, emerge ao que denominamos de questão disparadora: como elaboramos um modelo científico? Então, mãos à obra!

O roteiro prático a seguir é direcionado aos professores, tendo em vista as fundamentações teóricas que a proposta se baseia.

\section{Roteiro prático do estudante cientista}

Para além do macro, no cerne da unidade escolar, a temática proposta neste roteiro prático do estudante cientista permite contemplar as premissas da Base Nacional Comum Curricular (BNCC) referente aos Temas Contemporâneos Transversais (TCTs), inferindo na macroárea Meio Ambiente alicerçadas na perspectiva de aprendizagem de Rousseau (1712-1778), Vygotsky (1896-1934) e Kolb (1939).

Historicamente, a inovação da prática pedagógica proposta por JeanJaques Rousseau (1712-1778) deslocou o centro do processo de aprendizagem do docente e dos conteúdos, para as necessidades e interesses dos educandos, contradizendo as metodologias de aprendizagem apresentadas até então. Entretanto, essa mudança só teve repercussão em fins do século XIX e início do XX com o movimento escolanovista, representando a criação de novas escolas e métodos educacionais, orientados à aprendizagem ativa frente aos problemas do cotidiano (WENDT; DALBOSCO, 2012).

Nesse ensejo, a contribuição de Vygotsky (1988), na perspectiva da aprendizagem, com sua proposta técnica e inovadora para a época, quanto ao pensamento e a linguagem e a natureza do processo de desenvolvimento da criança e o papel da instrução no desenvolvimento, merece referência.

Vygotsky (1988) descreveu qual o papel a desempenhar pelo contexto social no desenvolvimento dos processos cognitivos das crianças. A interação 
social, nesse sentido, exerce papel crucial no desenvolvimento cognitivo. Essa abordagem apoia-se na concepção de um sujeito interativo que elabora conhecimentos sobre objetos, em processos necessariamente mediados pelo outro e constituídos pela linguagem.

A Teoria da Ciência, segundo Vygotsky (1988), tem o propósito de lidar com a validade do conhecimento científico e adicionado a esse plano teórico, há um plano psicológico que tenta explicar como os indivíduos extraem conhecimento de seu meio social, e fazem novas contribuições para o empreendimento coletivo da construção de conhecimento a que é chamado de ciência. Vygotsky (1988, p. 7) afirma que:

[...] a tarefa do cientista seria a de reconstruir a origem e curso do desenvolvimento do comportamento e da consciência. Não só todo fenômeno tem sua história, como essa história é caracterizada por mudanças qualitativas e quantitativas.

$\mathrm{Na}$ relação entre aprendizagem e desenvolvimento, Vygotsky (1988) aponta a existência de um nível a qual chamou de proximal ou potencial, que deve ser considerado na prática pedagógica, pois os educadores ao observar o desempenho observado no final do processo de ensino aprendizagem. Traduzindo à prática, quando o aluno não consegue realizar sozinho determinada tarefa, mas consegue realizar com a ajuda de outros colegas, está revelando seu nível de desenvolvimento proximal, que já contém aspectos e partes mais ou menos desenvolvidas de instituições, noções e conceitos.

Sustentada por Vygotsky, a Teoria de Aprendizagem de David Kolb (1984) apresenta quatro distintos estilos de aprendizagem, os quais são pautados em um círculo de aprendizagem de quatro estágios, e a partir de sua análise, demonstra um caminho para entender os estilos individuais de aprendizagem diferente das pessoas e uma explanação de um círculo de aprendizagem experiencial que se aplica a todos nós.

Kolb (1984) inclui esse círculo de aprendizagem como um princípio central de sua teoria de aprendizagem experiencial (experential learning), tipicamente expressa como ciclo de aprendizagem de quatro estágios, em que experiências imediatas ou concretas fornecem uma base para observações e reflexões. Tais observações e reflexões são assimiladas e destiladas em conceitos abstratos, produzindo novas implicações para a ação que podem ser ativamente testadas, as quais, por sua vez, criam novas experiências.

Ainda para Kolb (1984), idealmente este processo representa um círculo de aprendizagem ou espiral onde o aprendiz toca todas as bases, isto é, um círculo de experiência, reflexão, pensamento e atividade. Experiências concretas ou imediatas conduzem a observações e reflexões. Essas reflexões são então assimiladas (absorvidas e traduzidas) em conceitos abstratos com 
implicações para a ação, que a pessoa pode ativamente testar e com as quais experimentar o que, por sua vez, habilita a criação de novas experiências.

Por conseguinte, do ponto de vista do aprendizado, a escola que valoriza as experiências vivenciadas para um aprendizado mais completo pode desfrutar de resultados surpreendentes (KOLB, 1984).

Nesse ensejo, participativo e colaborativo proposto por Vygotsky (1988), em que o estudante é o protagonista do seu aprendizado e de Kolb (1984), em que a aprendizagem acontece por experiência concreta, observação reflexiva, conceitualização abstrata e experimentação ativa, consolida-se metodologicamente o presente roteiro.

Os conceitos serão aprendidos a partir das vivências dos estudantes, que são consideradas gatilhos cognitivos, desencadeados pelas propostas teórico-metodológicas da concepção do projeto, permitindo fazer o registro em forma experiencial, para que, no fim a mensagem dos próprios estudantes permita a elaboração conceitual do que preconiza a gestão e proteção das águas.

Além disso, a proposta torna possível engajar a escola em projetos comunitários de Educação Ambiental com viés participativo, ou seja, protagonistas de sua própria vida e atuando com responsabilidade e cidadania, tomando decisões com base em princípios éticos, democráticos, inclusivos, sustentáveis e solidários (BRASIL, 2017).

O projeto prático sequencialmente descrito tem como mote conector a Educação Ambiental, configurado um tema contemporâneo transversal, permitindo abarcar os diferentes objetos do conhecimento e empregando o método científico. Para sistematizar o conhecimento, propõe-se uma atividade que reforçará o papel da ciência e do emprego da metodologia científica na Educação Básica através da coleta de informações diretamente na natureza, a fim de, despertar a criticidade do educando para com os problemas evidenciados nas etapas anteriores.

\section{Texto motivador 4: Emprego do Método Científico}

Primeiro, nosso foco de estudos será o entorno de um ecossistema aquático, ou seja, o quanto as ações humanas relacionadas aos usos e ocupação da terra estão influenciando localmente no sistema hídrico.

A partir de agora, educador, organize as equipes de pesquisa (grupos de alunos), que serão os pesquisadores ou cientistas e comece a pensar nas etapas do Método Científico. Para isso, você precisa definir a sua unidade de estudo, ou seja, a Bacia Hidrográfica. Você pode utilizar uma nascente, um riacho ou rio que passe perto da escola, na rua, no quarteirão ou no bairro. Para dar início à aplicação nosso método científico, começaremos com o mapa mental do método científico e uma visita a campo. Reúna suas equipes, peguem seus bonés, suas garrafas de água, passem filtro solar, coloque calça 
comprida, blusa de malha e sapato fechado. Também não se esqueça de levar os materiais necessários para essa atividade (Figura 4). Vamos todos ao rio!

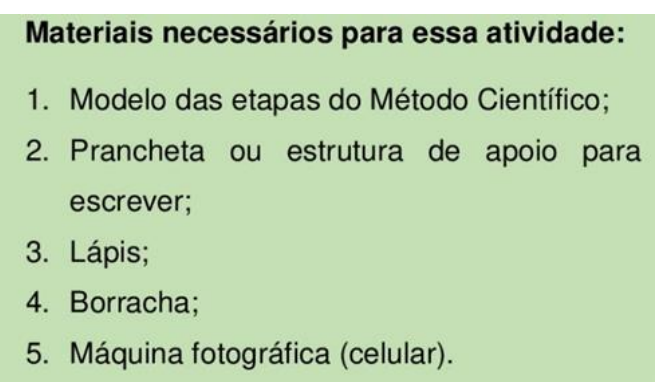

Figura 4: Materiais necessários para aula a campo

Fonte: Autores (2020).

A nossa primeira avaliação será, portanto, a aplicação do Método Científico: o que eu observo, o que eu quero saber sobre ecossistema aquático e o que eu concluo sobre minha observação. Assim, em grupos podemos completar o modelo abaixo (Figura 5).

\section{ETAPAS DO MÉTODO CIENTÍFICO}

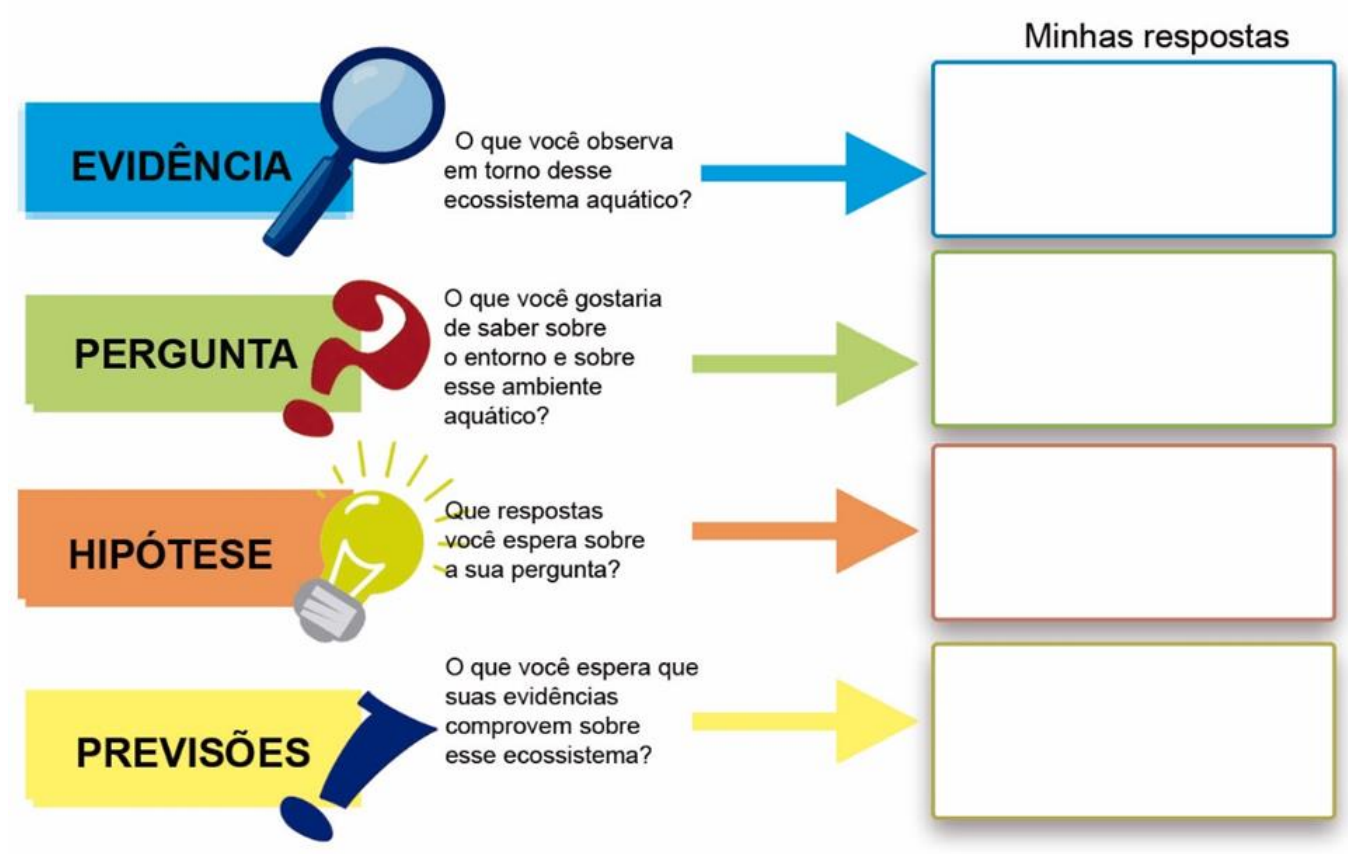

Figura 5: Aplicação do método científico.

Fonte: Autores (2020).

Agora vamos avaliar a respeito dos hábitats físicos que estão influenciando diretamente no ecossistema aquático.

Para direcionar essa avaliação de características de hábitats físicos importantes para a manutenção da estrutura do ecossistema aquático, segue 
um modelo sistemático proposto (tabela 2). Esta avaliação é feita visualmente e com uma única ida a campo, ou pode ser feita em escala temporal (visitas mensais, bimestrais, trimestrais, por exemplo) para observar se estão ocorrendo modificações durante a sua pesquisa.

Tabela 2: Avaliação do Ecossistema Aquático

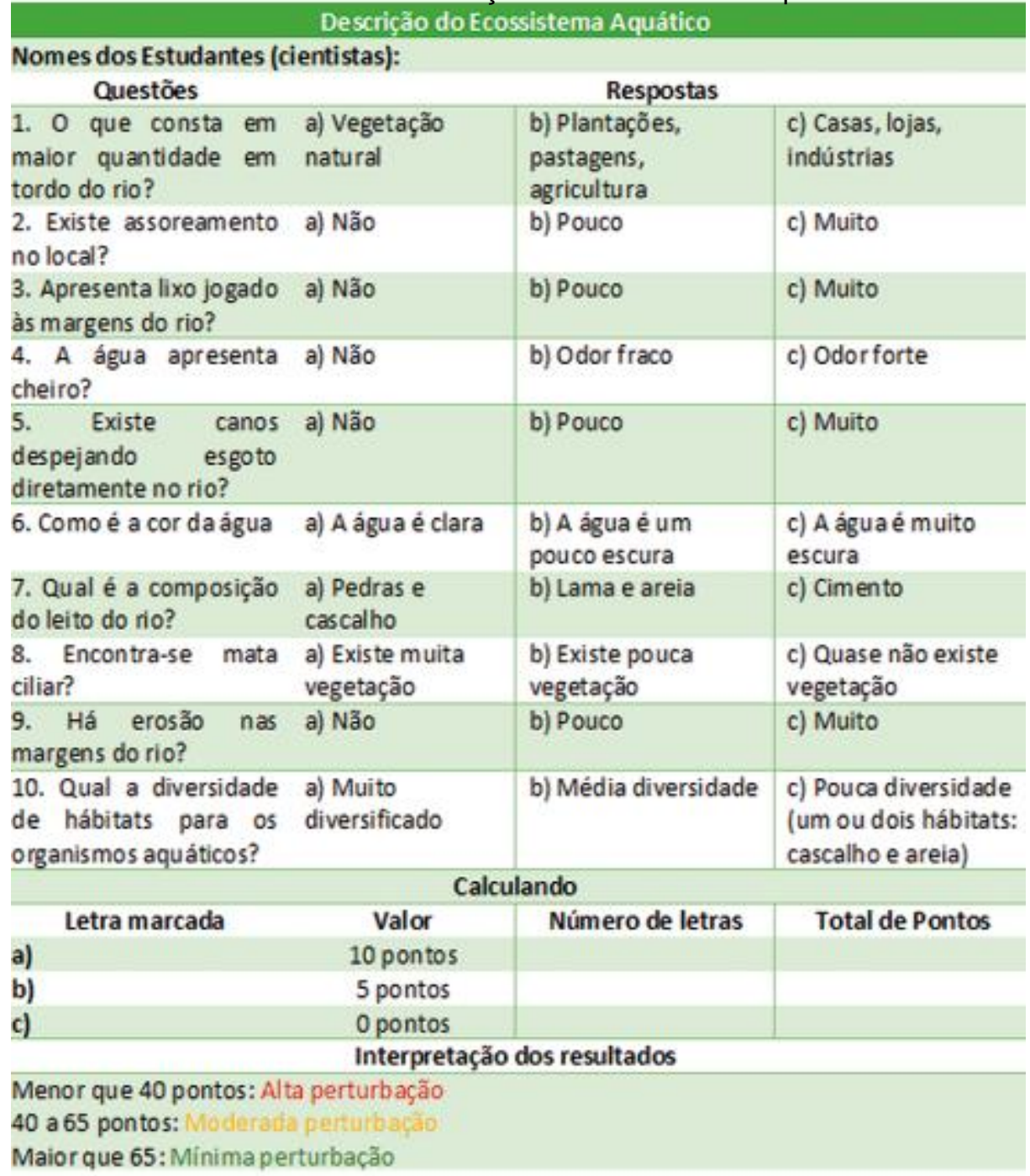

Fonte: Autores (2020).

A descrição do ecossistema acima será uma de suas bases metodológicas na busca de confirmar a sua hipótese sobre a estrutura do ecossistema aquático avaliado, ou a confirmação do que você propôs como hipótese. Cada pergunta representa um importante parâmetro indicador de manutenção das características naturais de um ecossistema aquático. A proposta é que você aplique este questionário observando o equivalente a 50 metros de comprimento de um trecho de rio. 


\section{Proposta de sistematização e avaliação dos resultados}

As características avaliadas procuram classificar a situação do rio em relação: à estabilidade das margens, presença de vegetação natural, transparência da água, erosão, homogeneização do leito, ao aumento do assoreamento, à composição do leito, à diversidade de hábitats para organismos e à presença de impactos humanos (CENIQUEL, 1992).

Cada uma das 10 questões avaliadas receberá pontuações variando de 0 (situação ruim), 5 (situação intermediária) e 10 pontos (situação boa), ou seja, apresentarão pontuações mais elevadas para melhor condição ecológica e pontuações mais baixas para condições ecológicas piores. O somatório dos valores destas 10 questões irá compor um índice local de hábitats físicos que pode variar de 0 a 100. Através do índice local, o estado atual do entorno do rio será então classificado em três categorias: minimamente perturbado ( $>65$ pontos), moderadamente perturbado (40 - 65 pontos) ou altamente perturbado ( 0 - 40 pontos). Podemos usar algumas imagens para comparação:

Ecossistema aquático minimamente perturbado: apresenta mata ciliar bem preservada, ausência ou áreas mínimas de erosão nas margens, reduzido acúmulo de sedimentos finos no leito (assoreamento ausente), oferece uma diversidade de hábitats para comunidades aquáticas, conforme demonstrado na figura 6.

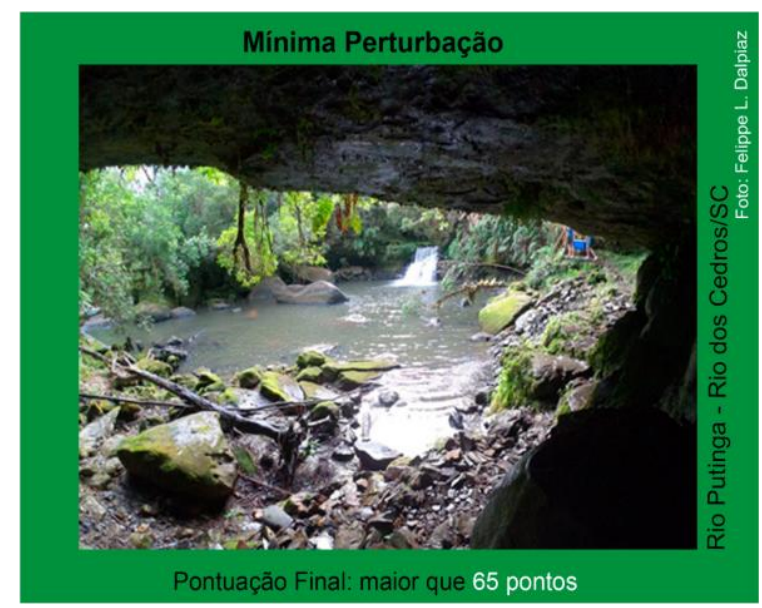

Figura 6: Ecossistema Aquático minimamente perturbado.

Fonte: Autores (2020).

Ecossistema aquático moderadamente perturbado: apresenta pouco ou moderado desmatamento e, como consequência, apresenta áreas de erosão nas margens e intenso assoreamento do leito com perda na diversidade de hábitats para comunidades aquáticas, como demostrado abaixo na figura 7 . 


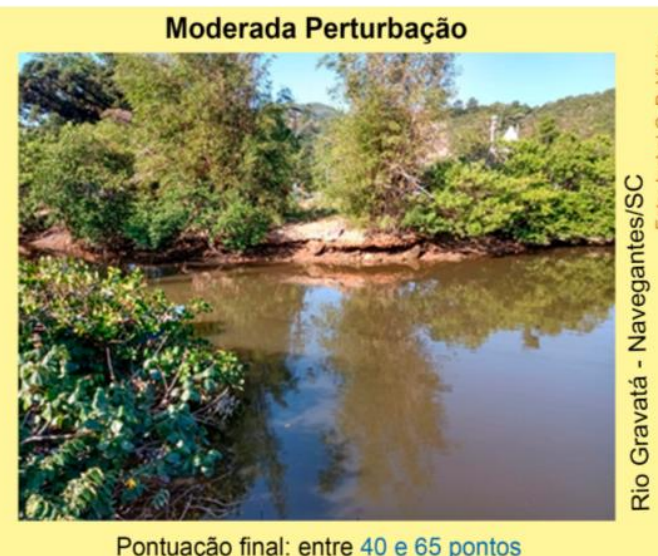

Figura 7: Ecossistema aquático moderadamente perturbado.

Fonte: Autores (2020).

Ecossistema aquático altamente perturbado: apresenta desmatamento e erosão intensos nas margens, leito assoreado e possíveis despejos de poluentes, como lixo e esgoto no seu entorno causando alteração drástica das comunidades aquáticas (Figura 8).

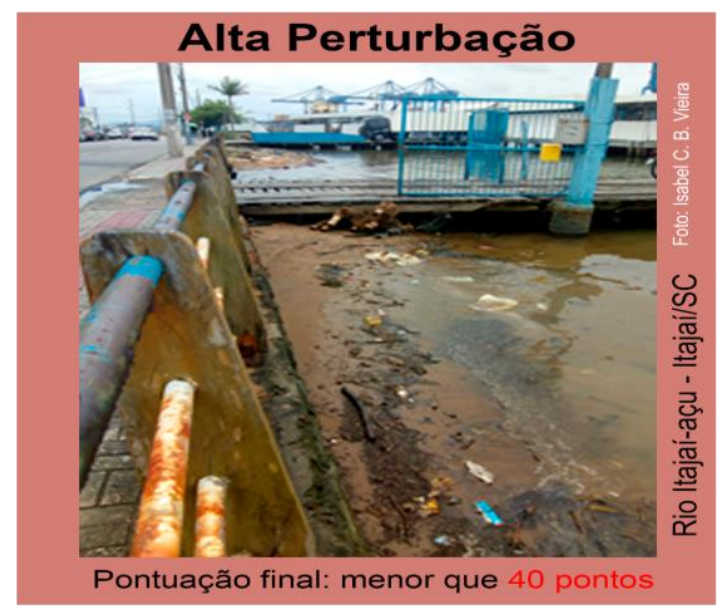

Figura 8: Ecossistema aquático altamente perturbado.

Fonte: Autores (2020).

Os índices são importantes ferramentas de avaliação ecológica por combinarem diferentes fatores e incorporarem informações distintas sobre a qualidade ambiental de um ecossistema (FRAGOSO et al., 2009). A proposta é, após a avaliação de diferentes questões, resultar na avaliação de qualidade ambiental de forma sistemática das influências ocorridas em um trecho de rio aplicando o método científico.

Vale lembrar que, a proposta da Base Nacional Comum Curricular do Ensino Fundamental na área de Ciências da Natureza tem como compromisso o desenvolvimento do letramento científico, que envolve a capacidade de 
compreender e interpretar o mundo (natural, social e tecnológico), e de transformá-lo com base nos aportes teóricos e processuais das ciências (BRASIL, 2017).

Nesse contexto, a construção dos textos motivadores serve como arcabouço teórico, a fim de consubstanciar a prática educativa de docentes transformando e sensibilizando seus educandos para a preservação do meio que os cercam, promovendo assim a formação em sua integralidade.

\section{Conclusões}

O presente roteiro abordou uma proposta teórico-prática alicerçado no desenvolvimento da aprendizagem proposto pela Base Nacional Comum Curricular (BNCC) e pelos Temas Contemporâneos Transversais (TCTs) na macroárea Meio Ambiente. Nessa perspectiva de aprendizagem, a mesma foi fundamentada, inferindo o educando como protagonista da educação, conforme as propostas de Rousseau (1712-1778), aprendizagem voltada para o interesse do educando, Vygotsky (1896-1934), na concepção de um sujeito interativo e de Kolb (1939), aprendizagem em um círculo de experiência, reflexão, pensamento e atividade.

Dessa forma, unindo o conhecimento de teóricos-educacionais, documentos norteadores e o planejamento escolar, a educação no Brasil se constrói com profissionais aguerridos e eruditas que formarão indivíduos na sua complexidade biológica, psicológica, cultural e social, ou seja, em sua integralidade. Nesse ensejo, a Educação Ambiental adentra nessa integração, transcendendo para além contexto escolar, transformando o educando antes passivo, em um ser crítico e ativo no meio em que vive, disposto a lutar por problemas sociais e ambientais vigentes, exercendo a cidadania e transformando vidas.

Diante do exposto, com práticas de ensino planejadas e fundamentadas, voltadas para a Educação Ambiental, onde o educando é protagonista da educação, teremos um ambiente escolar transformador, que supera a dicotomia homem e natureza e desenvolve a sensibilidade para com o meio ambiente e a qualidade de vida das futuras gerações.

\section{Referências}

BRASIL. Lei n.9.394, de 20 de dezembro de 1996. Estabelece as Diretrizes e Bases da Educação Nacional. Diário Oficial da República Federativa do Brasil, Poder Executivo, Brasília, DF, 21 dez. 1996. Disponível em: $<$ http://www.planalto.gov.br/ccivil 03/LEIS/L9394.htm>. Acesso em 16 abr. 2020.

BRASIL. SECRETARIA DE EDUCAÇÃO FUNDAMENTAL. Parâmetros Curriculares Nacionais: introdução aos parâmetros curriculares nacionais. 1997. 
BRASIL. Ministério da Educação. Secretaria de Educação Básica. Diretrizes Curriculares Nacionais Gerais da Educação Básica Diretoria de Currículos e Educação Integral. Brasília: MEC/ SEB, DICEI, 2013.

BRASIL. Lei no 13.005, 25 de junho de 2014. Aprova o Plano Nacional da Educação - PNE. Diário Oficial da União, Poder Legislativo, Brasília, DF. Disponível em: <http://www.planalto.gov.br/ccivil 03/ ato20112014/2014/lei//13005.htm>. Acesso em: 05 maio 2015.

BRASIL. Ministério da Educação. Secretaria de Educação Básica. Base Nacional Comum Curricular - Terceira versão. Brasília, DF: MEC/SEB, 2017.Disponível em: <http://basenacionalcomum.mec.gov.br> Acesso em 16 abr. 2020.

CABRAL, J. B. P. Estudo do processo de assoreamento em reservatórios. Caminhos de Geografia, v. 6, n. 14, 2005.

CARVALHO, I. C. M. Educação Ambiental: a formação do sujeito ecológico. São Paulo: Cortez, 2004.

CCOPA RIVERA, E. A. et al. Modelo sistêmico para compreender o processo de eutrofização em um reservatório de água. 2003.

CENIQUEL, M. Paisagem e habitat. Paisagem e ambiente, n. 4, p. 89-106, 1992.

CIÊNCIA. In Dicio, Dicionário online de Português. MICHAELIS: 2020. Disponível em: <https://michaelis.uol.com.br/modernoportugues/busca/portugues-brasileiro/ciencia/>. Acesso em 16 abr. 2020, v. 13, 2017.

DA COSTA RAMOS, L. B.; DA SILVA ROSA, P. R. O ensino de ciências: fatores intrínsecos e extrínsecos que limitam a realização de atividades experimentais pelo professor dos anos iniciais do ensino fundamental. Investigações em Ensino de Ciências, v. 13, n. 3, p. 299-331, 2016.

DA CIÊNCIA, G. et al. Uma breve história da Astronomia. 2006

FRAGOSO et al. Modelagem ecológica em ecossistemas aquáticos. Oficina de textos, 2009.

FRANÇA, J. S.; CALISTTO, M. Monitoramento participativo de rios urbanos: por estudantes-cientistas. 1. ed. Belo Horizonte, 2019. Disponível em:

$<$ http://labs.icb.ufmg.br/benthos/index arquivos/pdfs pagina/2019/Livro monito ramento/LivroCompleto.pdf >. Acesso em: 01 abr. 2020.

KOLB, D. Experimential learning: experience as the source of learning and development. New Jersey, Prentice Hall/Englewood Cliffs, 1984.

MINISTÉRIO DA EDUCAÇÃO (MEC). Temas contemporâneos transversais na BNCC. Proposta de Práticas de Implementação. p. 26, 2019. 
OMNÈS, R. Filosofia da ciência contemporânea. Unesp, 1996.

PICCOLI, A. DE S. et al. Environmental education as a social mobilization strategy to face water scarcity. Ciencia e Saude Coletiva, v. 21, n. 3, p. 797808, 2016.

PORTO, M. F. A; PORTO, R. L. Gestão de bacias hidrográficas. Estudos avançados, v. 22, n. 63, p. 43-60, 2008.

SILVA FERREIRA, D. Território, territorialidade e seus múltiplos enfoques na ciência geográfica. CAMPO-TERRITÓRIO: revista de geografia agrária, v. 9, n. 17,2014

SHIGEYOSI, W. T. Método científico na construção de modelos. Nova escola, São Paulo, nov. 2018. Disponível em: <https://novaescola.org.br/planode-aula/2483/metodo-cientifico-na-construcao-de-modelos >. Acesso em: 06, abr. 2020.

VIDAL, D. G.; FARIA FILHO, L. M. de. História da educação no Brasil: a constituição histórica do campo (1880-1970). Revista Brasileira de História, v. 23, n. 45, p. 37-70, 2003.

VIEIRA, I. C. B. Mapeamento da área de preservação permanente na margem norte do rio Itajaí-Açu em área urbana consolidada. Metodologias e Aprendizado, v. 1, p. 26-29, 2019

VYGOTSKY, L. S. Linguagem, desenvolvimento e aprendizagem. Tradução de Maria da Penha Villalobos. São Paulo: Ed. da USP, 1988.

WENDT, C. E.; DALBOSCO, C. A. Iluminismo pedagógico e educação natural em Jean-Jacques Rousseau. Educação (UFSM), v. 37, n. 2, p. 229-240, 2012.

WOLLMANN, E. M.; SOARES, F. A. A.; ILHA, P. V. As percepções de Educação Ambiental e Meio ambiente de professoras das séries finais e a influência destas em suas práticas docentes. Revista Brasileira de Pesquisa em Educação em Ciências, v. 15, n. 2, p. 387-405, 2015. 